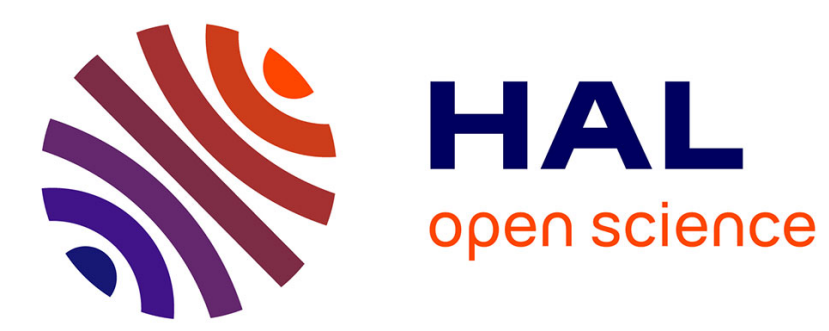

\title{
THE MEASUREMENT AND INTERPRETATION OF NeV 2-2 LINE INTENSITY RATIOS
}

Jérôme Lang

\section{To cite this version:}

Jérôme Lang. THE MEASUREMENT AND INTERPRETATION OF NeV 2-2 LINE INTENSITY RATIOS. Journal de Physique Colloques, 1988, 49 (C1), pp.C1-59-C1-62. 10.1051/jphyscol:1988110 . jpa-00227430

\section{HAL Id: jpa-00227430 https://hal.science/jpa-00227430}

Submitted on 1 Jan 1988

HAL is a multi-disciplinary open access archive for the deposit and dissemination of scientific research documents, whether they are published or not. The documents may come from teaching and research institutions in France or abroad, or from public or private research centers.
L'archive ouverte pluridisciplinaire HAL, est destinée au dépôt et à la diffusion de documents scientifiques de niveau recherche, publiés ou non, émanant des établissements d'enseignement et de recherche français ou étrangers, des laboratoires publics ou privés. 
THE MEASUREMENT AND INTERPRETATION OF NEV 2-2 LINE INTENSITY RATIOS

\author{
J. LANG \\ Rutherford Appleton Laboratory, Chilton, GB-Didcot OXI1 OQX, \\ Oxfordshire, Great-Britain
}

\begin{abstract}
A theta-pinch was used to produce NeV 2-2 spectral lines. The intensities of the lines were measured using a grazing incidence spectrometer which had been intensity calibrated by the branching ratios method. The electron temperature and density of the theta-pinch discharge were found by laser scattering. The measured intensity ratios are compared to theoretical predictions based on electron excitation rate coefficients calculated using the R-matrix close coupling method. For two of the measured ratios experiment and theory agree within the experimental uncertainty. For the other two ratios the theoretical prediction is greater than the experimental result.
\end{abstract}

\title{
1. Introduction.
}

Measurements of the intensities of spectral lines from a plasma of known electron temperature and density can yield electron excitation rate coefficients for comparison with theoretical values. This paper describes such an experiment using a theta-pinch plasma source to study the Clike ion $\mathrm{NeV}$. The absolute number density of $\mathrm{NeV}$ ions could not be reliably determined and thus accurate rate coefficients could not be deduced. Hovever, it was possible to measure line intensity ratios and compare them with those calculated using published theoretical excitation rate coefficients (in particular R-matrix close coupling calculations). Any disagreement outside the experimental error bars would indicate problems in the theoretical calculations. The results are of interest because line intensity ratios are extensively used to deduce electron temperatures and densities of astrophysical plasmas.

\section{Experiment.}

The NeV spectral lines were emitted by a theta-pinch plasma source. This consisted of a quartz tube $18 \mathrm{~cm}$ diameter surrounded by a $60 \mathrm{~cm}$ long single turn coil into which a capacitor bank was discharged. The firing cycle started with filling of the tube with $11 \mathrm{mTorr}$ of a $2 \% \mathrm{Ne}-\mathrm{in}-$ He mixture, followed by application of a bias magnetic field. Pre-ionisation and pre-heating discharges then occurred before the main discharge from the $16 \times 3 \mu \mathrm{F}$ capacitors charged to $35 \mathrm{kV}$. Observations were made during the $6 \mu \mathrm{sec}$ of the first half cycle when a plasma of about $4 \mathrm{~cm}$ diameter was formed.

To make comparison of measured and theoretical line intensity ratios the electron temperature and density of the plasma must be known. These were determined by Thomson scattering of pulsed ruby laser radiation from the free electrons in the plasma. The Doppler-broadened profile of the scattered radiation was detected on a six-channel spectrometer which allowed the line profile and hence electron temperature to be measured for each laser discharge. The electron density was measured from the total radiation scattered, the efficiency of the scattering system being obtained from measurements of Rayleigh scattering from a gas of known cross section $[1,2]$. At the time of peak $\mathrm{NeV}$ emission, the electron temperature was $6.1 \times 10^{5} \mathrm{~K}( \pm 10 \%)$ and the electron density was $6.2 \times 10^{15} \mathrm{~cm}^{-3}( \pm 14 \%)$.

The spectroscopic measurements were made using the apparatus shown in Figure 1. The $1.5 \mathrm{~m}$ Ebert spectrometer was used from $2000 \AA$ to $7000 \AA$. The vacuum two channel $1 \mathrm{~m}$ grazing incidence spectrometer was fitted with a $1200 \mathrm{line} / \mathrm{mm}$ platinised grating. The front exit slit was used from $80 \AA$ to $450 \AA$ and the rear exit slit was used from $450 \AA$ to $1000 \AA$. The Ebert 
spectrometer was intensity calibrated from $2000 \AA$ to $4000 \AA$ using a deuterium lamp and from $3500 \AA$ to $7000 \AA$ using a tungsten lamp, both lamps being supplied by the NPL. The intensity calibration of the vacuum spectrometer was accomplished using the branching ratios method whereby an intensity calibration can be transferred from one spectral range where it is known (ie that of the Ebert spectrometer) to one where it is needed by making measurements of suitable line pairs which must satisfy several criteria: they must arise from common upper levels; they must have well calculated, or measured, branching ratios of spontaneous radiative transition probabilities ( $A$ values); and they must lie one in each of the relevant spectral ranges. The line pairs used in the calibration were from Li-like and H-like ions. The calibration of the rear exit slit was both from the spectral range of the Ebert spectrometer and from the front exit slit. Further details of the calibration are given in the papers by Lang [3] and Lang et al.[4].

Checks showed that opacity did not affect the results of the calibration or the measurements.

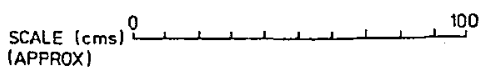

$$
\begin{aligned}
& \text { SCALE (cms) } \\
& \text { (APPROX) }
\end{aligned}
$$

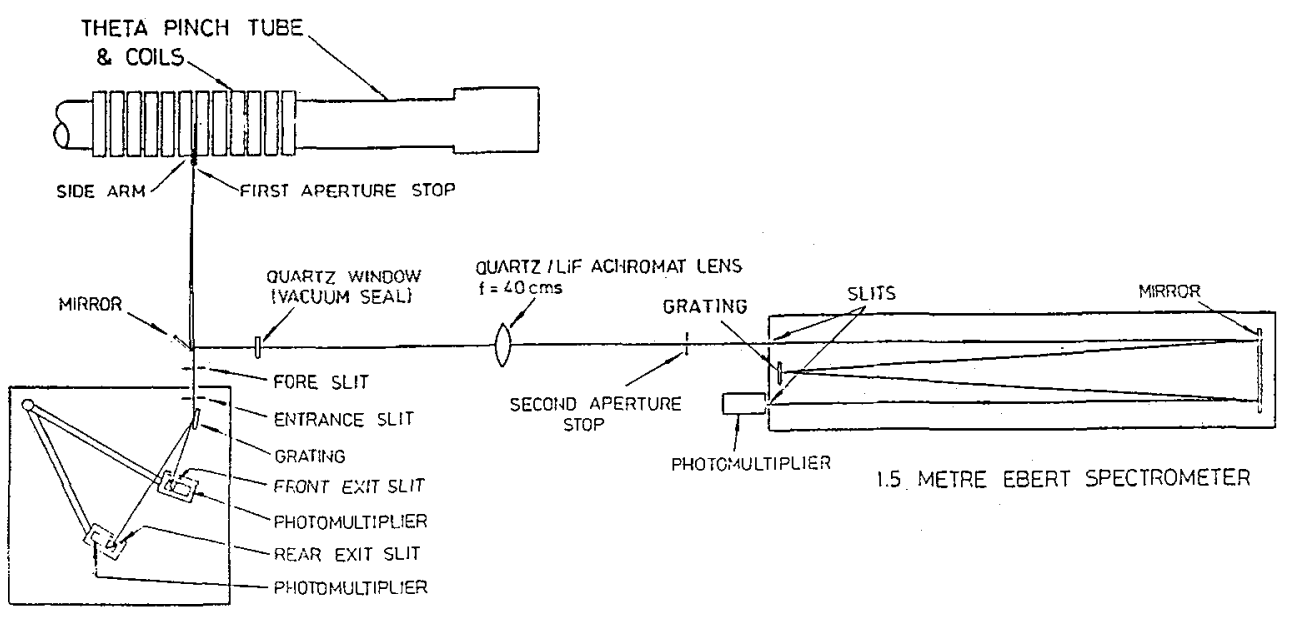

I METRE GRAZING INCIDENCE VACUUM SPECTROMETER

Fig. 1.- The experimental arrangement.

\section{Theory.}

To obtain the theoretical line intensity ratios, the statistical equilibrium equations were solved for the lowest twelve terms in $\mathrm{NeV}\left(2 s^{2} 2 p^{2}{ }^{3} P,{ }^{1} D\right.$ and ${ }^{1} S, 2 s 2 p^{3}{ }^{5} S,{ }^{3} D,{ }^{3} P,{ }^{1} D,{ }^{3} S$ and ${ }^{1} P$ and $2 p^{4}{ }^{3} P,{ }^{1} D$ and $\left.{ }^{1} S\right)$. For the electron excitation data, results of R-matrix close coupling calculations were used. $[5,6,7,8]$. The transition probabilities used were those of Aggarwal [8], supplemented by three results for forbidden transitions from Fischer and Saha [9]. The data were organised and the line intensities calculated using the computer programs described by Gordon and Summers [10].

\section{Comparison of experiment and theory.}

The comparisons of experimental and theoretical line intensity ratios are given in figures 2, 3,4 and 5. The $2 s^{2} 2 p^{2}{ }^{3} P-2 s 2 p^{3}{ }^{3} D$ transition was used as a reference in each case. The experimental ratio is shown with its error bars and the theoretical ratio is given for two electron densities. In figure 5 the $2 s^{2} 2 p^{2}{ }^{1} S-2 s 2 p^{3}{ }^{1} P$ transition accounts for less than $12 \%$ of the total predicted intensity. 


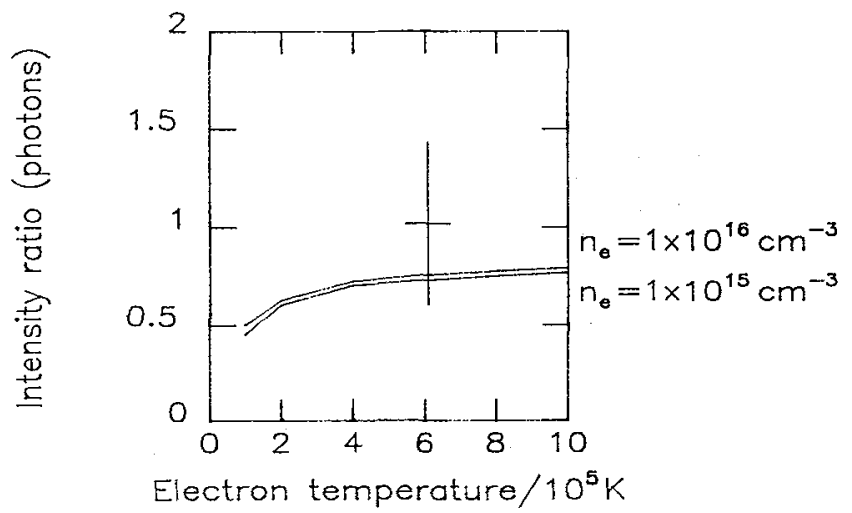

Fig. 2.- The ratio $\mathrm{I}\left(2 s^{2} 2 p^{2}{ }^{3} P-2 s 2 p^{3}{ }^{3} P\right) / \mathrm{I}\left(2 s^{2} 2 p^{2}{ }^{3} P-2 s 2 p^{3}{ }^{3} D\right)(482 \AA$ and $571 \AA)$.

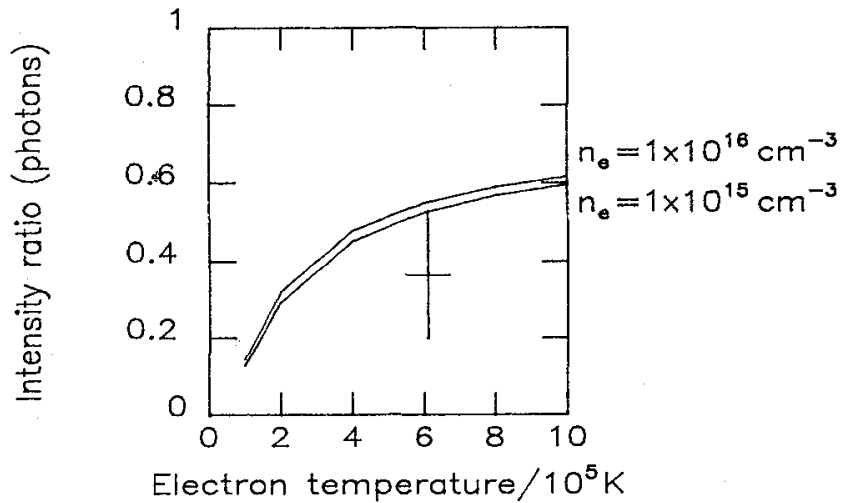

Fig. 3.- The ratio $\mathrm{I}\left(2 s^{2} 2 p^{2}{ }^{3} P-2 s 2 p^{3}{ }^{3} S\right) / \mathrm{I}\left(2 s^{2} 2 p^{2}{ }^{3} P-2 s 2 p^{3}{ }^{3} D\right)(359 \AA$ and $571 \AA)$.

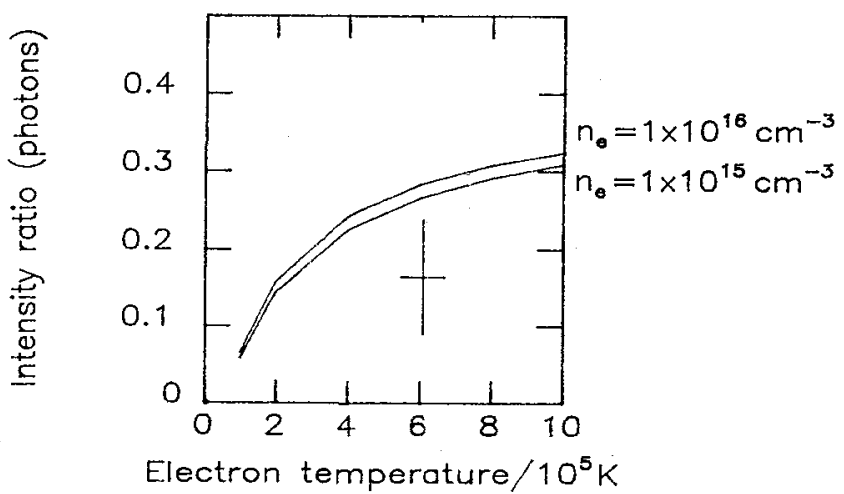

Fig. 4.- The ratio $\mathrm{I}\left(2 s^{2} 2 p^{2}{ }^{1} D-2 s 2 p^{3}{ }^{1} P\right) / \mathrm{I}\left(2 s^{2} 2 p^{2}{ }^{3} P-2 s 2 p^{3}{ }^{3} D\right)(365 \AA$ and $571 \AA)$. 


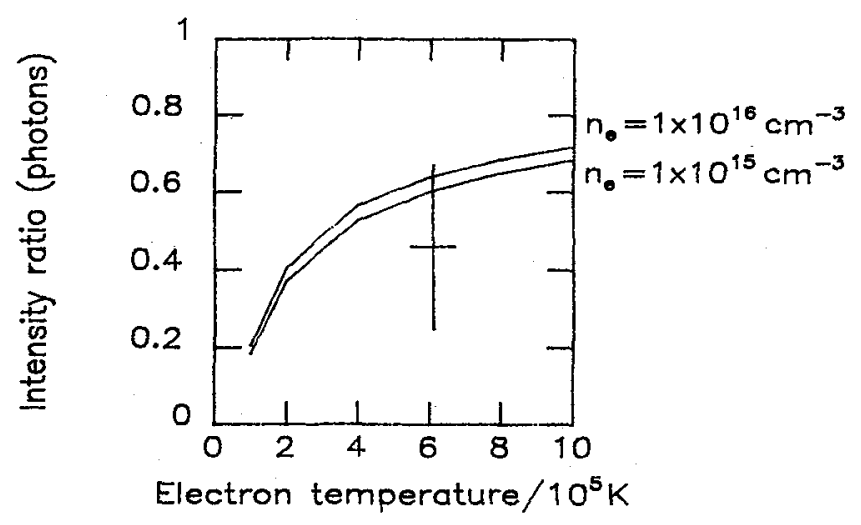

Fig. 5.- The ratio $\left(\mathrm{I}\left(2 s^{2} 2 p^{2}{ }^{1} D-2 s 2 p^{3}{ }^{1} D\right)+\mathrm{I}\left(2 s^{2} 2 p^{2}{ }^{1} S-2 s 2 p^{3}{ }^{1} P\right)\right) /$ $\mathrm{I}\left(2 s^{2} 2 p^{2}{ }^{3} P-2 s 2 p^{3}{ }^{3} D\right)(417,416 \AA$ and $571 \AA)$.

\section{Conclusions.}

For two of the ratios experiment and theory agree within the experimental uncertainty. For the other two ratios the theoretical prediction is greater than the experimental result, in one case by about $70 \%$.

\section{References}

[1] Lang, J., Maclaren, W.M. and Spurrett, P.H., J. Phys. E: Sci. Inst. 18 (1986) 213.

[2] Lang, J., Hardcastle, R.A. and Spurrett, P.H., J. Phys. D: Appl. Phys. (in press).

[3] Lang, J., J. Phys. B: At. Mol. Phys. 16 (1983) 3907.

[4] Lang, J., Hardcastle, R.A., McWhirter, R.W.P. and Spurrett, P.H., J. Phys. B;

At. Mol. Phys. 20 (1987) 43.

[5] Baluja, K.L., Burke, P.G. and Kingston, A.E., J. Phys. B: At. Mol. Phys. 13 (1980) 4675.

[6] Aggarwal, K.M., Astrophys. J. Supp. Ser. 54 (1984) 1.

[7] Aggarwal, K.M., Astrophys. J. Supp. Ser. 58 (1985) 289.

[8] Aggarwal, K.M., Astrophys. J. Supp. Ser, 61 (1986) 699.

[9] Fischer, C.F. and Saha, H.P., Phys. Scr. 32 (1985) 181.

[10] Gordon, H. and Summers, H.P., Culham Lab. Rept. CLM-R250 (1985). 